\title{
Ballistic Impact Simulation of Ceramic/Metal Armor Structures
}

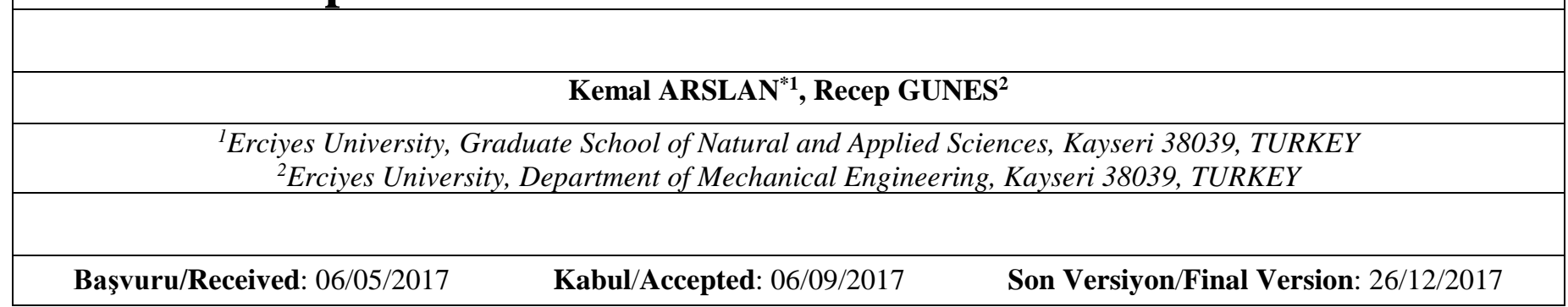

\begin{abstract}
The study presents a comparative numerical investigation on ballistic performance of ceramic/metal armor structures. 2D axisymmetric numerical model was developed for ballistic impact simulations using LS-DYNA ${ }^{\circledR}$ finite element software. The armor structures included combinations of boron carbide $\left(\mathrm{B}_{4} \mathrm{C}\right)$, Al6061-T6 and 4340 steel constituents. The interfaces in the armor structure were modelled with an epoxy resin adhesive. In order to define proper material behavior, Johnson-Holmquist-Ceramics material model for $\mathrm{B}_{4} \mathrm{C}$ and Plastic-Kinematic material model for Al6061-T6, 4340 steel and epoxy resin was used. The armor structures were subjected to $7.62 \mathrm{~mm}$ ogive-nosed steel projectile impact. In the first section, the influence of back plate material on the ballistic performance of the armor structure for bi-layers ceramic/metal configuration (ceramic front face and metal back plate) was investigated for Al6061-T6 and 4340 steel materials under same thickness and areal density. In the second section, the effect of removing half thickness of the metal constituent from the back plate and placing on the front face was investigated for both Al6061T6 and 4340 steel materials. Finally, the influence of adhesive thickness on the ballistic performance of the armor structure was investigated. Perforation response of the armor structures were examined in terms of residual velocity of the projectile and damage mechanisms of the armor structure.
\end{abstract}

\section{Key Words}

"Ballistic impact; Finite element analysis; Ceramic/Metal armor; Perforation” 


\section{INTRODUCTION}

Ceramics have been one of the most important component for armor structures with their high specific strength, hardness and thermal resistance properties. However, they are not preferred as a monolithic armor by reason of their brittle structure. Therefore, they are widely used as front face plate with ductile materials in order to deform projectile geometry, decrease the effect of shock waves on substrates and spread the impact load over a large region. In order to provide structural integrity and absorb the remaining kinetic energy of the projectile, more ductile and tougher materials are used as back plate in ceramic-faced armor structures. There are generally two different options for back plate material: metals and fiber-reinforced polymer (FRP) composites. FRP composites can be used as back plate for better performance, but metals can be preferable by reason of being more economical than FRP composites and providing protective function [López-Puente et al. (2005)]. The use of ceramic/metal bi-layer armor structures provides lighter designs compared to monolithic metal armors showing the same or better ballistic protection. Several researchers have investigated the ballistic impact response of different ceramic/metal armor structures using experimental, numerical and analytical methods or combinations of these methods [Zaera and Sánchez-Gálvez (1998), Zaera et al. (2000), Lee and Yoo (2001), Arias et al. (2003), Gonçalves et al. (2004), Mahdu et al. (2005), Chi et al. (2013), Serjouei et al. (2015), Tang and Wen (2017)].

In this study, a numerical study was carried out on ballistic performance of ceramic/metal armor structures subjected to $7.62 \mathrm{~mm}$ ogive-nosed steel projectile impact using 2D axisymmetric finite element model. The effect of different back plate material under same thickness and areal density, transforming the armor structure from bi-layers to tri-layers configuration under same areal density and the influence of adhesive thickness were investigated.

\section{NUMERICAL MODEL}

Ballistic impact simulation of ceramic/metal armor structures was performed using explicit finite element code, LS-DYNA ${ }^{\circledR}$. The armor structures were subjected to $60^{\circ}$ conical-nosed cylindrical steel projectile with $7.62 \mathrm{~mm}$ diameter.

In the armor structures, boron carbide $\left(\mathrm{B}_{4} \mathrm{C}\right)$ ceramic constituent, Al6061-T6 and 4340 steel metal constituents were used. The interfaces in the armor structure were modelled with an epoxy resin adhesive. The dimensions of the steel projectile were $7.62 \mathrm{~mm}$ in diameter and $28.1 \mathrm{~mm}$ in length [Fawaz et al. (2004)]. 2D axisymmetric numerical model shown in Fig. 1 was developed for ballistic impact simulations. In the first section, bi-layers ceramic/metal configuration, ceramic front face and metal back plate, was considered and the influence of the back plate material on the ballistic performance of the armor structure was investigated for two different metal, Al6061-T6 and 4340 steel, under same thickness and areal density. In the second section, tri-layers metal/ceramic/metal configuration was considered in order to prevent ceramic fragmentation from the front face and compared with the bi-layers configuration. In tri-layers configuration, half thickness of the metal constituent was removed from the back plate and placed on the front face. Namely, the total weight of the armor structure remained constant except the second adhesive layer. Finally, the effect of adhesive thickness for the armor structure with 4340 steel back plate was investigated for two different thickness. The total armor thickness was considered as $15 \mathrm{~mm}$ with $5 \mathrm{~mm}$ thickness of ceramic front face and $10 \mathrm{~mm}$ thickness of metal back plate. For the first and second section investigation, the thickness of the adhesive layer was modelled as $0.5 \mathrm{~mm}$ and in order to investigate the effect of adhesive thickness, the thicknesses of $0.5 \mathrm{~mm}$ and $1.0 \mathrm{~mm}$ were considered.

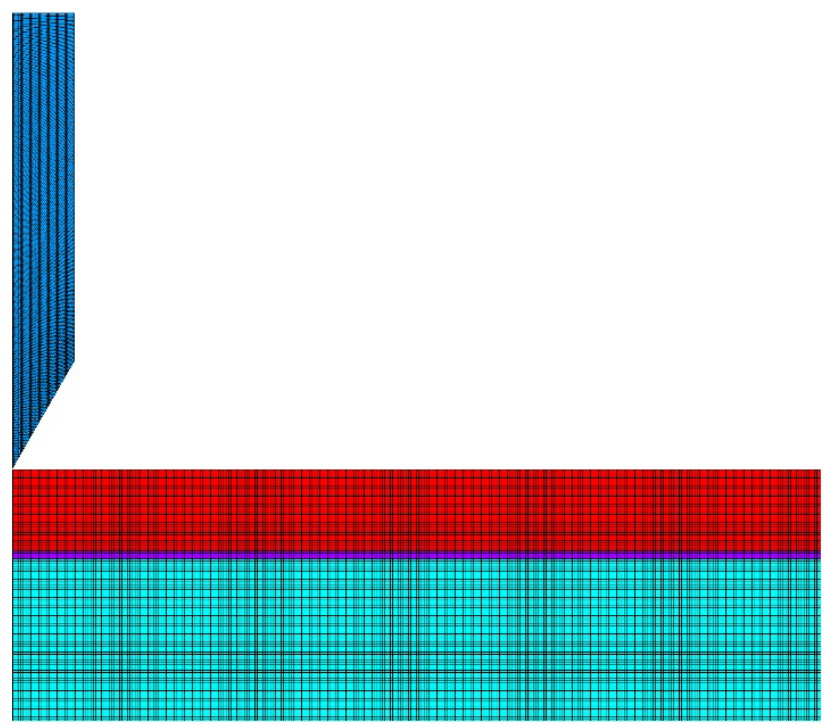

Fig. 1. Finite element models of the ceramic/metal armor structure and steel projectile. 
The projectile and armor structure were represented with 2D and 4-node solid element with its axisymmetric option and the element size of the finite element model was determined as $0.125 \mathrm{~mm}$ performing successive analyses. The constituents of the armor were represented with two different material models in LS-DYNA ${ }^{\circledR}$. The steel projectile, Al6061-T6, 4340 steel and epoxy resin were modelled using an elastic-plastic material model, MAT_PLASTIC_KINEMATIC (MAT_003) [Kreig and Key (1976)] and the ceramic constituent $\mathrm{B}_{4} \mathrm{C}$ was modelled with a plasticity damage model, MAT_JOHNSON_HOLMQUIST_CERAMICS (MAT_110) material model which is useful for modelling ceramics, glass and other brittle materials [Johnson and Holmquist (1993)]. The material model parameters of the steel projectile [Fawaz et al. (2004), Tasdemirci et al. (2012)], Al6061-T6 [Nechitailo and Batra (1998)], 4340 steel [Nechitailo and Batra (1998)], epoxy resin [Huang and Chen (2016)] and B ${ }_{4}$ C [Johnson and Holmquist (1999)] were listed in Table 1 and Table 2, respectively.

Table 1. Material properties of the steel projectile, Al6061-T6, 4340 steel and epoxy resin.

\begin{tabular}{|l|c|c|c|c|}
\hline Material parameters & Steel projectile & Al6061-T6 & 4340 steel & Epoxy resin \\
\hline Density $\left(\mathrm{kg} / \mathrm{m}^{3}\right)$ & 7890 & 2700 & 7850 & 1150 \\
\hline Young's modulus (GPa) & 202 & 73.3 & 200 & 1.14 \\
\hline Poisson's ratio & 0.3 & 0.33 & 0.29 & 0.49 \\
\hline Yield stress (MPa) & 1069 & 298 & 970 & 43 \\
\hline Tangent modulus (GPa) & 2 & 0.38 & 0.47 & 0.036 \\
\hline Effective plastic strain at failure & 0.80 & 0.85 & 0.77 & 0.60 \\
\hline
\end{tabular}

Table 2. Johnson-Holmquist-Ceramics material model input parameters for $\mathrm{B}_{4} \mathrm{C}$.

\begin{tabular}{|l|l|l|l|l|l|l|}
\hline Density $\left(\mathrm{kg} / \mathrm{m}^{3}\right)$ & G $(\mathrm{GPa})$ & A & B & C & M & N \\
\hline 2510 & 197 & 0.927 & 0.7 & 0.005 & 0.85 & 0.67 \\
\hline & & & & & & \\
\hline EPSI & T $(\mathrm{GPa})$ & SFMAX & HEL (GPa) & PHEL (GPa) & BETA & \\
\hline 1.0 & 0.26 & 0.2 & 19 & 8.71 & 1.0 & \\
\hline & & & & & & \\
\hline D1 & D2 & K1 (GPa) & K2 (GPa) & K3 (GPa) & & \\
\hline 0.001 & 0.5 & 233 & -593 & 2800 & & \\
\hline
\end{tabular}

G - Shear modulus; A - Intact normalized strength parameter; B - Fractured normalized strength parameter; C - Strength parameter (for strain rate dependence); $\mathrm{M}$ - Fractured strength parameter (pressure exponent); $\mathrm{N}$ Intact strength parameter (pressure exponent); EPSI - Reference strain rate; $\mathrm{T}$ - Maximum tensile pressure strength; SFMAX - Maximum normalized fractured strength; HEL - Hugoniot elastic limit; PHEL - Pressure component at the Hugoniot elastic limit; BETA - Fraction of elastic energy loss converted to hydrostatic energy; D1 - Parameter for plastic strain to fracture; D2: Parameter for plastic strain to fracture (exponent); K1 - First pressure coefficient (equivalent to the bulk modulus); K2: Second pressure coefficient; K3 - Third pressure coefficient

In order to simulate failure mechanisms of the metal constituents and epoxy resin, effective plastic strain at failure value (erosion criterion) of the materials which is available for Plastic-Kinematic material model was defined. For Johnson-Holmquist-Ceramics material model, the erosion criterion is based on failure strain (FS) value where the element is deleted when the plastic strain exceeds the identified failure strain. The FS value is a material erosion criterion and is not involved in the damage calculations. It allows to remove highly distorted redundant elements from the calculations and does not affect the simulation predictions [Cronin et al. (2003)]. The FS value was defined as 1.25 in this study. In addition, in order to avoid high level distortions in elements, Flanagan-Belytschko viscous form hourglass option [Flanagan and Belytschko (1981)] was defined.

In order to consider mechanical contact between projectile and armor structure and possible self-contacting surfaces, CONTACT_2D_AUTOMATIC_SINGLE_SURFACE algorithm was defined. The contact between the ceramic and metal constituents was provided by modelling an epoxy resin adhesive layer in finite element model. The adhesive layer was modelled as tied with the ceramic front face and metal back plate. Furthermore, an approximate effective plastic strain at failure value of 0.60 was defined for epoxy resin in order to model possible separations at the interface.

The armor structure was clamped with a distance of $10 \mathrm{~mm}$ from the edge and the velocity of the projectile was considered as 1000 $\mathrm{m} / \mathrm{s}$ which perforates the armor structures by reason of comparison of the configurations in terms of residual velocity of the projectile. Besides, different configurations of the armor structure were also examined in terms of damage mechanisms. 


\section{RESULTS AND DISCUSSION}

Ballistic impact performance of ceramic/metal armor structures was investigated under 7.62 mm ogive-nosed steel projectile impact and simulation results were examined in terms of residual velocity of the projectile and damage mechanisms of the armor structure.

In the first section, the effect of the back plate material on the ballistic performance of the armor structure was investigated for two different metal, Al6061-T6 and 4340 steel. The metal back plates were examined under same thickness and areal density. The time history of the projectile velocity for same thickness of the back plates was given in Fig. 2. The residual velocity of the projectile for Al6061-T6 and 4340 steel back plates was $635.7 \mathrm{~m} / \mathrm{s}$ and $170.5 \mathrm{~m} / \mathrm{s}$, respectively. The residual velocity of the projectile for 4340 steel was about 73.2\% less than for Al6061-T6. On the other hand, the weight of the armor with 4340 steel was 2.3 times more than with Al6061-T6 under same thickness configuration. The damage shapes of the armor structures for same thickness of the back plates were given in Fig. 3. The armor structures with different metal back plates showed different damage mechanisms. In general, the ceramic front plate exhibited extremely radial cracks and rarely axial cracks while ductile perforation occurred in the metal back plates. In details, the strength and stiffness of the back plate influenced the damage level of the ceramic front plate. For the armor structure with 4340 steel back plate, damage level (crack size, crack propagation and ceramic conoid) occurred in ceramic front plate was higher than with Al6061-T6 back plate by reason of stiffer structure of 4340 steel. Al6061-T6 provided more ductile behavior to the armor structure. Moreover, shear cracks resulted in the adhesive layer and separation occurred at the interface for 4340 steel back plate whereas any failure did not observe in the adhesive layer for Al6061-T6 back plate.

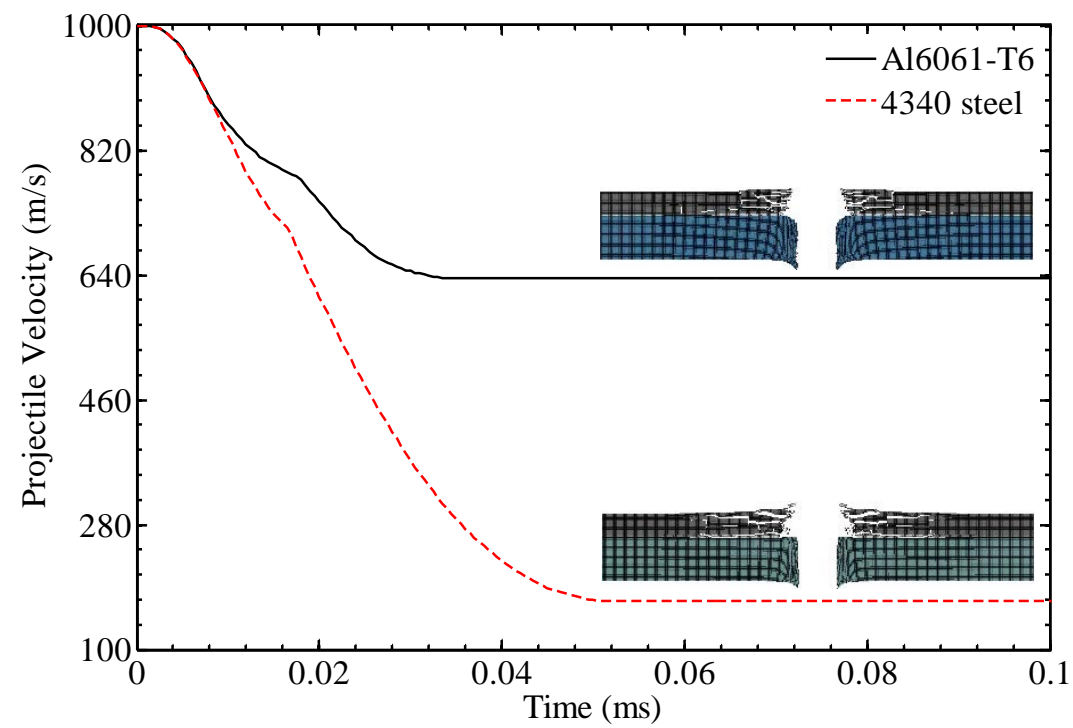

Fig. 2. The time history of the projectile velocity for Al6061-T6 and 4340 steel back plates under same thickness.
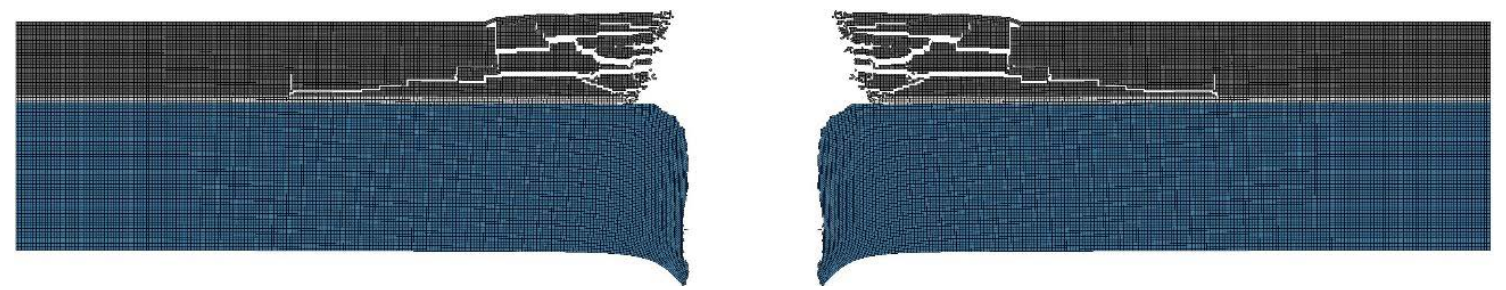

(a) Al6061-T6 back plate
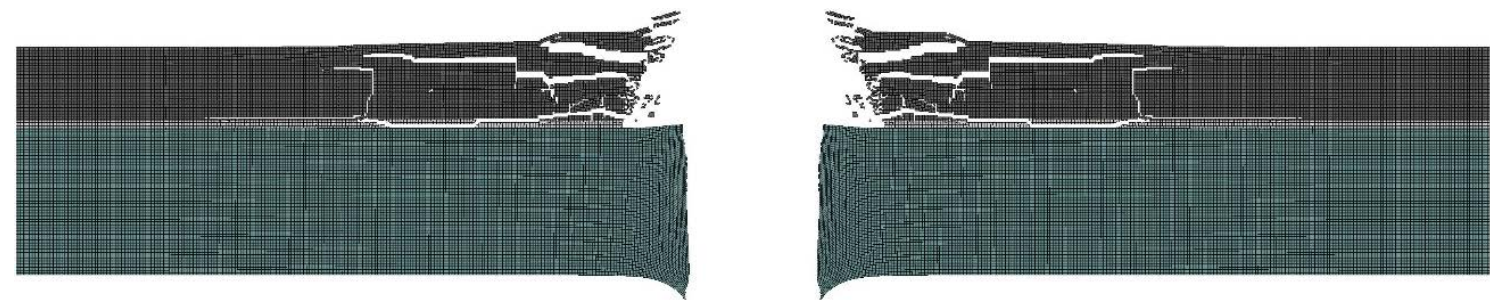

(b) 4340 steel back plate

Fig. 3. The damage shapes of the armor structure for Al6061-T6 and 4340 steel back plates under same thickness. 
For the same areal density configuration, the thickness of 4340 steel back plate for same areal density with 10 mm thickness of Al6061-T6 was determined as about $3.44 \mathrm{~mm}$. The time history of the projectile velocity for same areal density of the back plates was given in Fig. 4. The residual velocity of the projectile for Al6061-T6 and 4340 steel back plates was $635.7 \mathrm{~m} / \mathrm{s}$ and $592.9 \mathrm{~m} / \mathrm{s}$, respectively. The residual velocity of the projectile for 4340 steel was about 6.7\% less than for Al6061-T6. Although the thickness of 4340 steel back plate was 2.9 times less than Al6061-T6, the armor structure with 4340 steel back plate exhibited better ballistic performance in terms of residual velocity of the projectile. The damage shapes of the armor structures for same areal density of the back plates were given in Fig. 5. The damage level such as crack propagation for 4340 steel back plate decreased for same areal density configuration compared with same thickness configuration by reason of decrement in the stiffness related with reduction in the plate thickness. The shear cracks occurred in same thickness configuration did not resulted in same areal density configuration for adhesive layer.

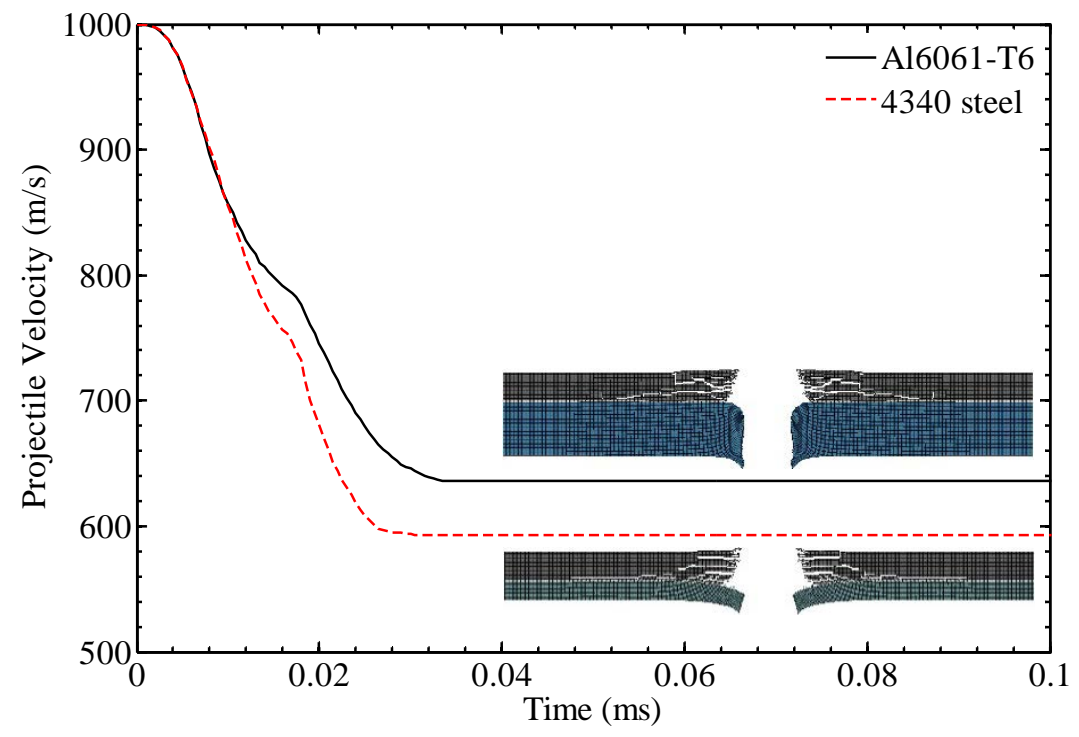

Fig. 4. The time history of the projectile velocity for Al6061-T6 and 4340 steel back plates under same areal density.
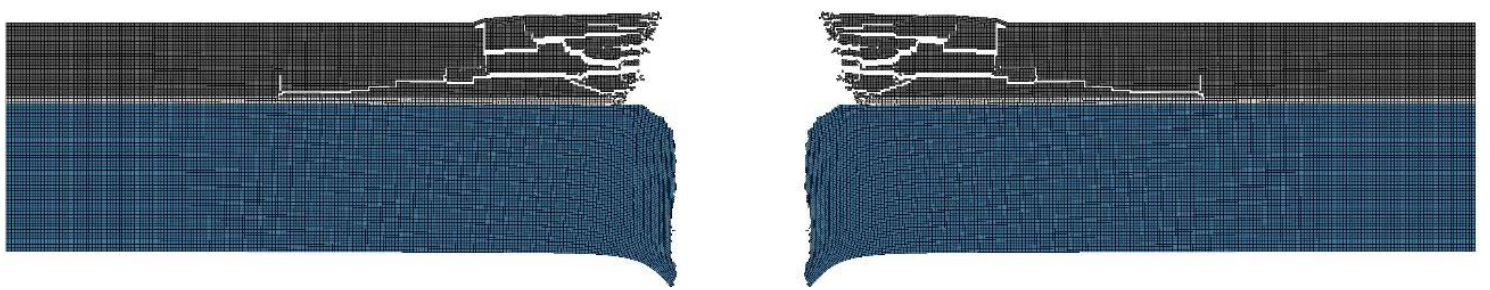

(a) Al6061-T6 back plate
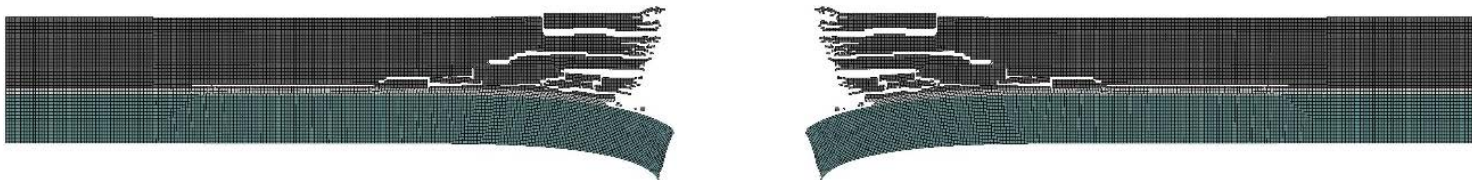

(b) 4340 steel back plate

Fig. 5. The damage shapes of the armor structure for Al6061-T6 and 4340 steel back plates under same areal density.

In the second section, the effect of removing half thickness of the metal constituent from the back plate and placing on the front face on the residual velocity of the projectile and damage mechanisms of the armor structure was investigated. In other words, bilayers ceramic/metal and tri-layers metal/ceramic/metal configurations were compared. The aim of placing half thickness of the metal constituent on the front face was to investigate prevention level of the top metal layer from ceramic fragmentation. These configurations were investigated for both Al6061-T6 and 4340 steel back plates. The time history of the projectile velocity for bilayers and tri-layers configurations of Al6061-T6 was given in Fig. 6. The residual velocity of the projectile for bi-layers and trilayers configurations was $635.7 \mathrm{~m} / \mathrm{s}$ and $720.7 \mathrm{~m} / \mathrm{s}$, respectively. The residual velocity of the projectile for bi-layers configuration was about $11.8 \%$ less than for tri-layers configuration. Transforming the armor structure from bi-layers to tri-layers configuration reduced to ballistic performance of the armor structure in terms of residual velocity of the projectile. The damage shapes of the armor structures for bi-layers and tri-layers configurations of Al6061-T6 were given in Fig. 7. In general, a considerable 
enhancement was not observed in tri-layers configuration in terms of damage level. However, tri-layers configuration partially prevented the fragmentation at the top side of the ceramic plate.

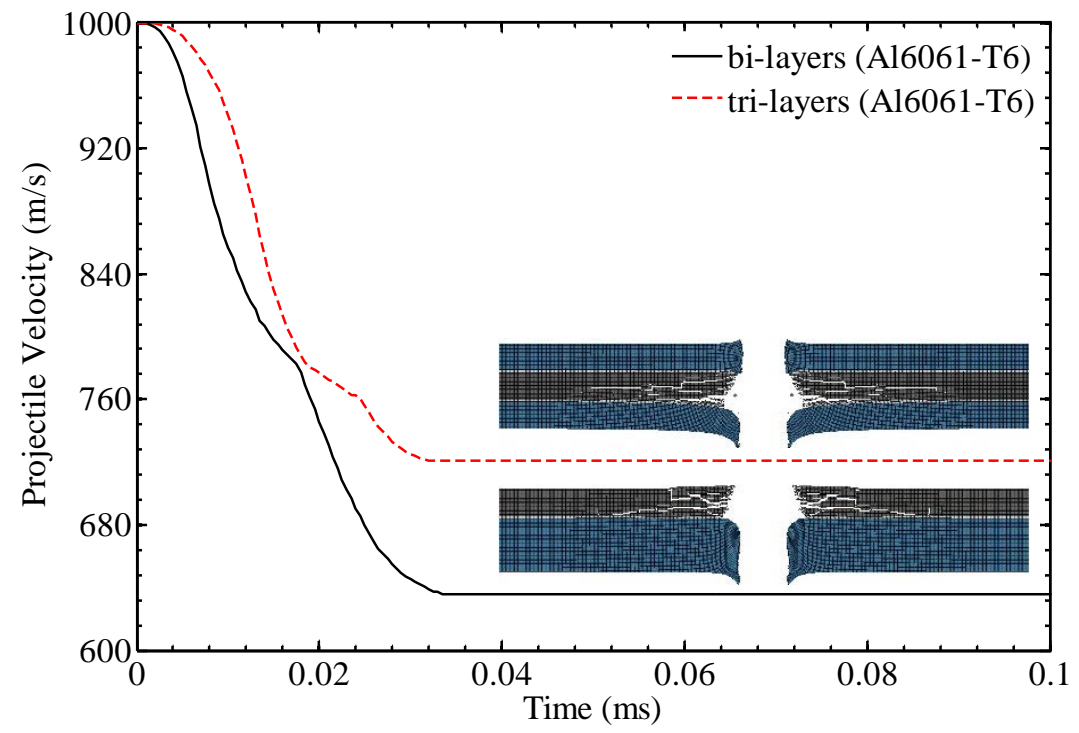

Fig. 6. The time history of the projectile velocity for bi-layers and tri-layers configurations of Al6061-T6.
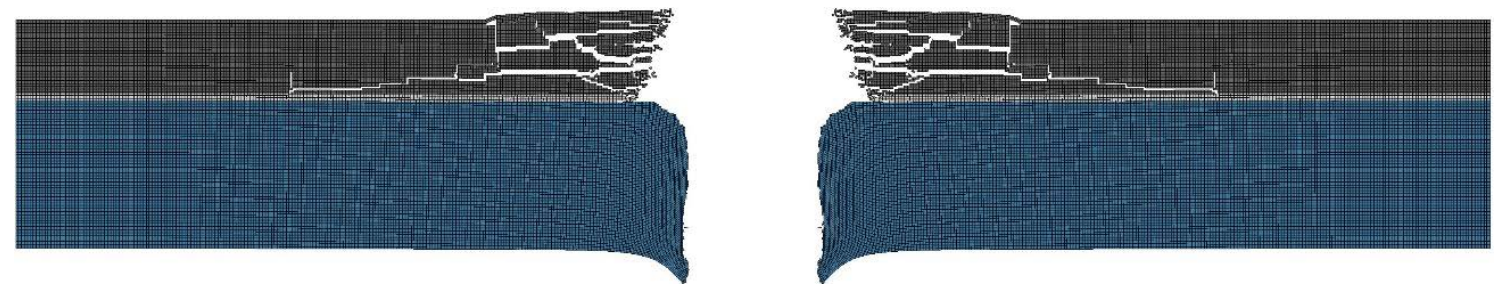

(a) Bi-layers configuration (Al6061-T6)
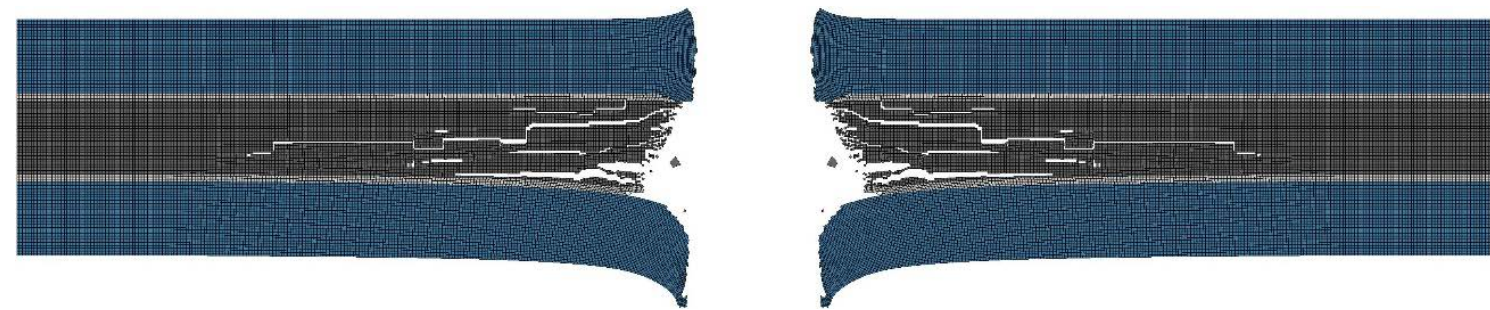

(b) Tri-layers configuration (Al6061-T6)

Fig. 7. The damage shapes of the armor structure for bi-layers and tri-layers configurations of Al6061-T6.

The time history of the projectile velocity for bi-layers and tri-layers configurations of 4340 steel was given in Fig. 8. The residual velocity of the projectile for bi-layers and tri-layers configurations was $170.5 \mathrm{~m} / \mathrm{s}$ and $297.3 \mathrm{~m} / \mathrm{s}$, respectively. The residual velocity of the projectile for bi-layers configuration was about $42.7 \%$ less than for tri-layers configuration. Similar to the armor structure with Al6061-T6 back plate, transforming the armor structure from bi-layers to tri-layers configuration reduced to ballistic performance of the armor structure in terms of residual velocity of the projectile. The damage shapes of the armor structures for bi-layers and tri-layers configurations of 4340 steel were given in Fig. 9. In contrary to the armor structure with Al6061-T6 back plate, tri-layers configuration of 4340 steel decreased the damage occurred in ceramic plate. In tri-layers configuration, crack formation was concentrated at the bottom side of the ceramic plate and top side of the ceramic plate was prevented from fragmentations occurred in bi-layers configuration. Although ballistic performance of the armor structure with 4340 steel constituent decreased in terms of residual velocity of the projectile, damage and fragmentation level occurred in ceramic plate enhanced. 


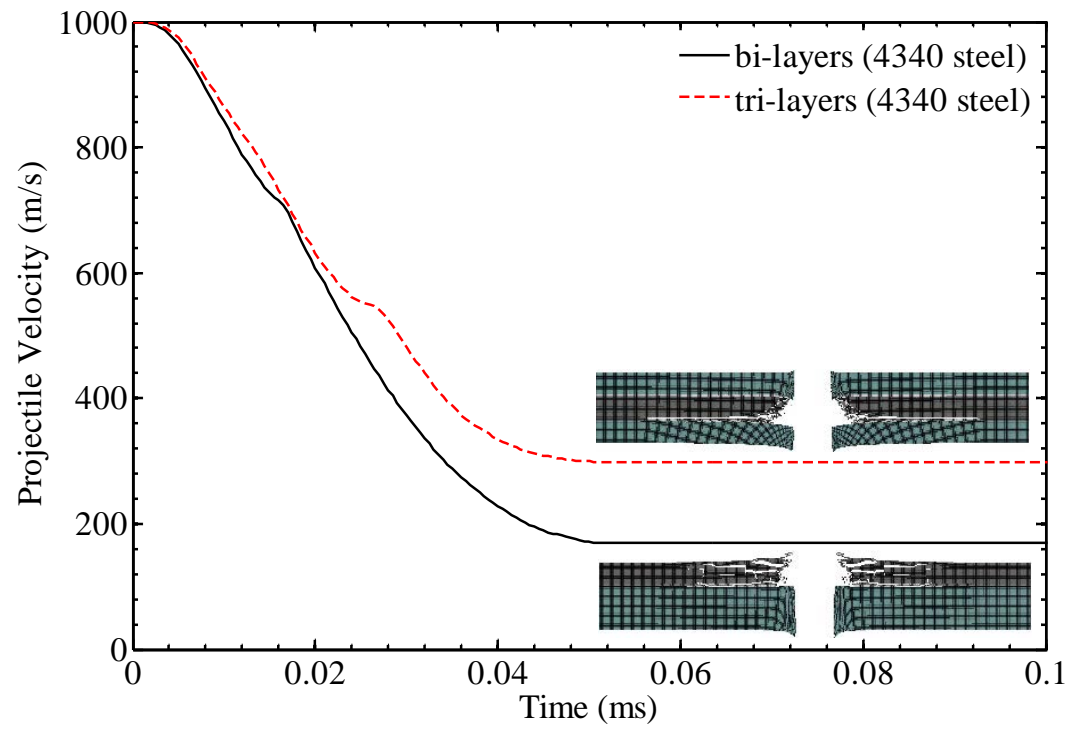

Fig. 8. The time history of the projectile velocity for bi-layers and tri-layers configurations of 4340 steel.
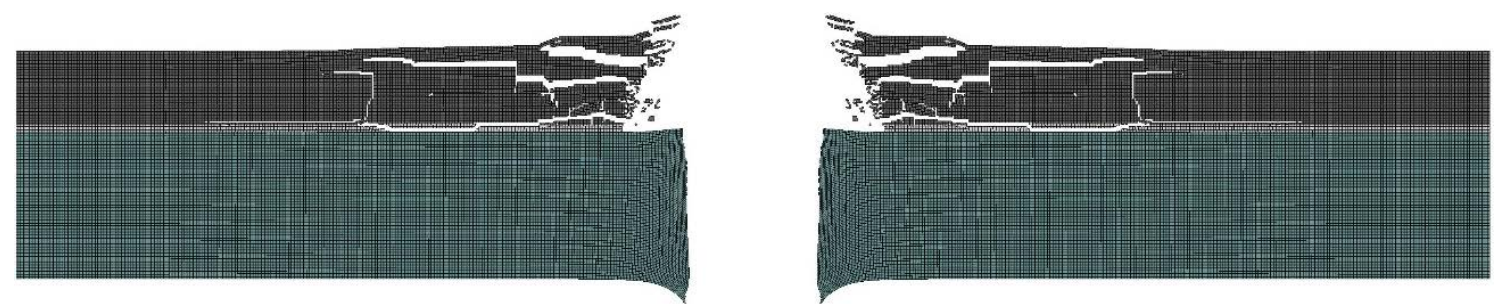

(a) Bi-layers configuration (4340 steel)
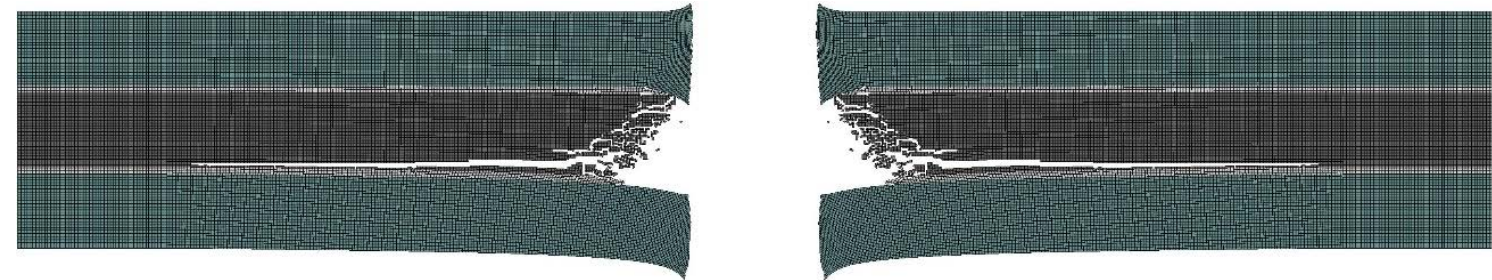

(b) Tri-layers configuration (4340 steel)

Fig. 9. The damage shapes of the armor structure for bi-layers and tri-layers configurations of 4340 steel.

The influence of adhesive thickness $(t)$ was investigated for the armor structure with 4340 steel back plate for two different thicknesses, $0.5 \mathrm{~mm}$ and $1.0 \mathrm{~mm}$. The time history of the projectile velocity for different adhesive thicknesses was given in Fig. 10. The residual velocity of the projectile for the adhesive thickness of $0.5 \mathrm{~mm}$ and $1.0 \mathrm{~mm}$ was $170.5 \mathrm{~m} / \mathrm{s}$ and $214.8 \mathrm{~m} / \mathrm{s}$, respectively. The residual velocity of the projectile for the adhesive thickness of $1.0 \mathrm{~mm}$ was about $26.0 \%$ more than for the adhesive thickness of $0.5 \mathrm{~mm}$. Increasing the adhesive thickness from $0.5 \mathrm{~mm}$ to $1.0 \mathrm{~mm}$ caused to decrement in the ballistic performance of the armor structure in terms of the residual velocity of the projectile similar to the study of López-Puente et al. (2005). The damage shapes of the armor structures for different adhesive thicknesses were given in Fig. 11. The crack formation occurred in the ceramic front plate decreased, however the size of ceramic fragments increased with increasing adhesive thickness. For the adhesive thickness of $0.5 \mathrm{~mm}$, more crack paths, longer crack propagation and smaller ceramic fragments occurred in the ceramic front plate. Additionally, no shear cracks was observed in the adhesive layer for the thickness of $1.0 \mathrm{~mm}$ whereas shear cracks occurred in the adhesive layer for the thickness of $0.5 \mathrm{~mm}$. 


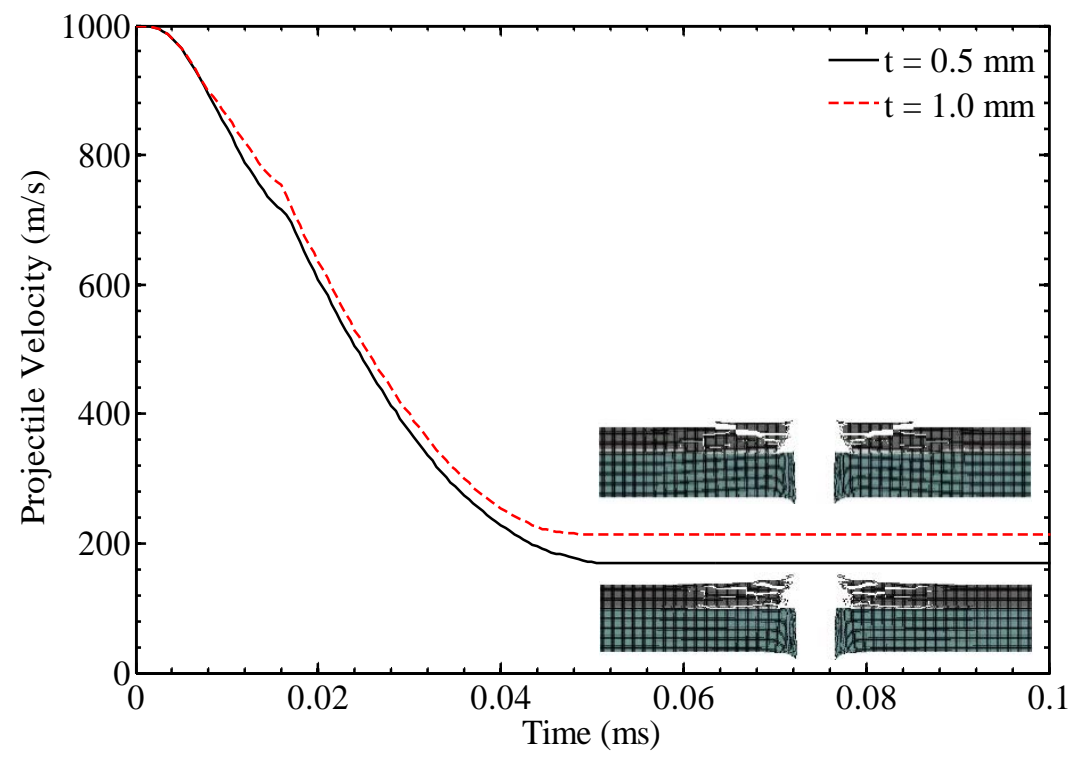

Fig. 10. The time history of the projectile velocity for different adhesive thicknesses (4340 steel back plate).
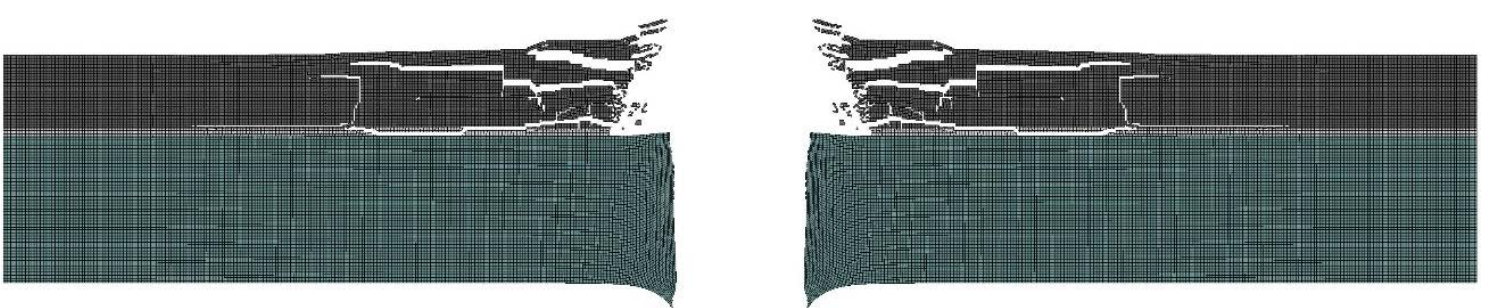

(a) $t=0.5 \mathrm{~mm}$
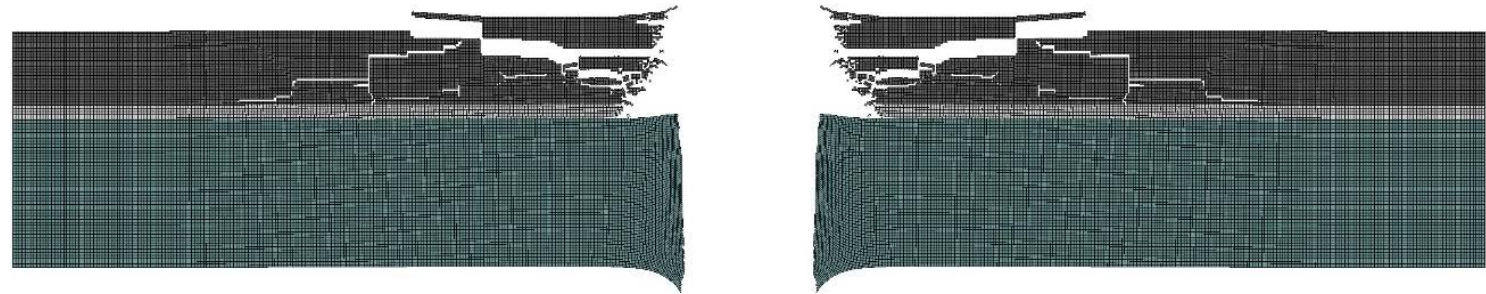

(b) $t=1.0 \mathrm{~mm}$

Fig. 11. The damage shapes of the armor structure for different adhesive thicknesses (4340 steel back plate).

\section{CONCLUSION}

A comparative numerical study was performed on ballistic impact response of ceramic/metal armor structures subjected to 7.62 mm ogive-nosed steel projectile. The simulation results were examined in terms of residual velocity of the projectile and damage mechanisms of the armor structures.

- The bi-layers armor structure with 4340 steel back plate exhibited better ballistic performance than with Al6061-T6 back plate under both same thickness and areal density in terms of residual velocity of the projectile.

- The damage level (crack size, crack propagation and ceramic conoid) occurred in ceramic front plate for 4340 steel back plate was higher than for Al6061-T6 back plate by reason of stiffer structure of 4340 steel under both same thickness and areal density configuration.

- Shear cracks resulted in the adhesive layer for only the armor structure with 4340 steel back plate for same thickness configuration.

- Transforming the armor structures from bi-layers to tri-layers configuration reduced to the ballistic performance of the armor in terms of residual velocity of the projectile for both back plates. 
- Tri-layers configuration of 4340 steel decreased the damage occurred in ceramic plate and top side of the ceramic plate was fully prevented from fragmentations whereas an enhancement was not observed in tri-layer configuration of Al6061-T6 in general and ceramic fragmentation at the top side of the ceramic plate partially prevented.

- Increasing the adhesive thickness from $0.5 \mathrm{~mm}$ to $1.0 \mathrm{~mm}$ reduced to ballistic performance of the armor structure in terms of the residual velocity of the projectile.

- Increasing the adhesive thickness from $0.5 \mathrm{~mm}$ to $1.0 \mathrm{~mm}$ prevented the shear cracks in the adhesive layer, crack formation and propagation in the ceramic front plate and however caused to increment in the size of ceramic fragments.

Finally, this is a comparative numerical investigation on the ballistic performance of a ceramic/metal armor and authors do not claim that the armor structure can be practicable in this investigated form. It should be verified by experimental tests and optimized in terms of geometrical and mechanical properties of the constituents.

\section{REFERENCES}

Arias, A., Zaera, R., López-Puente, J., \& Navarro, C. (2003). Numerical modeling of the impact behavior of new particulate-loaded composite materials. Composite Structures, 61, 151-159.

Cronin, D.S., Bui, K., Kaufmann, C., Mclntosh, G., \& Berstad, T. (2003). Implementation and validation of the Johnson-Holmquist ceramic material model in LS-DYNA. $4^{\text {th }}$ European LS-DYNA Users Conference, 22-23 May, Ulm/Germany, 47-59.

Chi, R., Serjouei, A., Sridhar, I., \& Tan, G.E.B. (2013). Ballistic impact on bi-layer alumina/aluminium armor: A semi-analytical approach. International Journal of Impact Engineering, 52, 37-46.

Flanagan, D.P., \& Belytschko, T. (1981). A uniform strain hexahedron and quadrilateral and orthogonal hourglass control. International Journal for Numerical Methods in Engineering, 17, 679-706.

Fawaz, Z., Zheng, W., \& Behdinan, K. (2004). Numerical simulation of normal and oblique ballistic impact on ceramic composite armours. Composite Structures, 63, 387-395.

Gonçalves, D.P., de Melo, F.C.L., Klein, A.N., \& Al-Qureshi, H.A. (2004). Analysis and investigation of ballistic impact on ceramic/metal composite armour. International Journal of Machine Tools \& Manufacture, 44, 307-316.

Huang, C., \& Chen, Y. (2016). Design and impact resistant analysis of functionally graded $\mathrm{Al}_{2} \mathrm{O}_{3}-\mathrm{ZrO}_{2}$ ceramic composite. Materials and Design, 91, 294-305.

Johnson, G.R., \& Holmquist, T.J. (1993). An improved computational model for brittle materials. High-Pressure Science and Technology, 981-984.

Johnson, G.R., \& Holmquist, T.J. (1999). Response of boron carbide subjected to large strains, high strain rates and high pressures. Journal of Applied Physics, 85, 8060-8073.

Kreig, R.D., \& Key, S.W. (1976). Implementation of a time dependent plasticity theory into structural computer programs. Constitutive Equations in Viscoplasticity: Computational and Engineering Aspects, eds., J.A. Stricklin and K.J. Saczalski, ASME, New York, 125-137.

López-Puente, J., Arias, A., Zaera, R., \& Navarro, C. (2005). The effect of the thickness of the adhesive layer on the ballistic limit of ceramic/metal armours. An experimental and numerical study. International Journal of Impact Engineering, 32, 321-336.

Lee, M., \& Yoo, Y.H. (2001). Analysis of ceramic/metal armour systems. International Journal of Impact Engineering, 25, 819829.

Mahdu, V., Ramanjaneyulu, K., Bhat, T.B., \& Gupta, N.K. (2005). An experimental study of penetration resistance of ceramic armour subjected to projectile impact. International Journal of Impact Engineering, 32, 337-350.

Nechitailo, N.V., \& Batra, R.C. (1998). Penetration/Perforation of aluminum, steel and tungsten plates by ceramic rods. Computers \& Structures, 66, 571-583.

Serjouei, A., Chi, R., Zhang, Z., \& Sridhar, I. (2015). Experimental validation of BLV model on bi-layer ceramic-metal armor. International Journal of Impact Engineering, 77, 30-41.

Tang, R.T., \& Wen, H.M. (2017). Predicting the perforation of ceramic-faced light armors subjected to projectile impact. International Journal of Impact Engineering, 102, 55-61.

Tasdemirci, A., Tunusoglu, G., \& Guden, M. (2012). The effect of the interlayer on the ballistic performance of ceramic/composite armors: Experimental and numerical study. International Journal of Impact Engineering, 44, 1-9.

Zaera, R., \& Sánchez-Gálvez, V. (1998). Analytical modelling of normal and oblique ballistic impact on ceramic/metal lightweight armours. International Journal of Impact Engineering, 21, 133-148.

Zaera, R., Sánchez-Sáez, S., Pérez-Castellanos, J.L., \& Navarro, C. (2000). Modelling of the adhesive layer in mixed ceramic/metal armours subjected to impact. Composites Part A: Applied Science and Manufacturing, 31, 823-833. 